\title{
An Empirical Study of Country Risk Adjustments to Market Multiples Valuation in Emerging Markets: the case for Russia
}

\author{
Ivashkovskaya $\mathbf{I}^{17},{\text { Kuznetsov } \mathbf{I}^{18}}^{18}$
}

Valuation in emerging markets is always a challenge. The existence of sovereign risk and capital market segmentation as well as small trading volumes and narrow domestic capital market make it difficult to identify peer companies for market multiples valuation without cross- border comparables. This paper investigates the practical implementation of market multiples valuation in emerging markets when the analyst should involve peer companies from developed markets. Companies with comparable operational parameters bear different values on different financial markets. The problem of unavoidable difference among national stock markets exists, that is why methods of cross-border multiples' corrections are called for. We address cross-border corrections procedures for adjusting multiples to a sovereign risk to find out the role and the extent of these type of adjustments in valuation. We are using the samples of Russian and US companies to test three different adjustments' techniques: the sovereign spread, the relative market coefficients and the regression approach.

\section{Introduction}

This paper investigates the practical implementation of multiples valuation in emerging markets. The main purposes of this work are: first, to find out whether crossborder correction procedures are necessary or not; and, second, to build a relative valuation methodology which will have broad practical application.

The market multiples valuation approach is considered to be the most complex valuation methodology, which implies that the value of the common shareholder equity is determined by the price at which it can be sold on the stock exchange. In other words, the fairest estimate of a company value can be expressed in terms of the selling price of a similar business recorded by the market. Hence, the meaning of the term 'similar' becomes crucial in establishing the correct set of market comparables. The majority of empirical and fundamental researches showed that the company value is determined by its operating and financial characteristics, market position, and the perspective of its further development. Therefore, comparable companies should have similar relationships between their prices and key operational characteristics such as profitability, payout ratio, growth rate, return and etc.. Those factors play a significant role in explaining the return from the point of view of a prospective investor.

However, in case of peer companies lack within the border of one emerging market analysts do often look for comparables from developed markets. Such approach should be carefully reformulated taking into account the fact that the allure of an emerging market is primarily determined by different market imperfections like entry barriers, information asymmetry, economic and political risk, government regulations and etc.. Such factors affect the country and other firm's specific risks. That is why investors' perceptions of the value of the same asset traded on different markets differ. Similarly companies with comparable operational parameters carry different values on different financial markets. The problem of unavoidable difference among national stock markets

\footnotetext{
${ }^{17}$ Professor of Finance, Corporate Finance Center, Head of Corporate Finance Department, Higher School of Economics, Moscow, Russia ivashkovskaya@yandex.ru

18 Corporate Finance Center, Higher School of Economics ivan.kuznetsov@ru.ey.com
} 
exists, that is why methods of multiples corrections are called for. On the other hand, adjustment procedures are usually ranked among the last ones to perform, despite the fact that they account for the major part of company value.

This paper addresses the issue of building the most reliable correction methodology accounting for country risk, and finding a suitable multiples valuation methodology, which will take into account cross-border effects on comparable companies. To do so we have analyzed two markets: the Russian one, as an emerging market, and the U.S. one, as a developed market, over the period from 2002 to 2005.

The remainder of this paper is organized as follows: into the first section we review the relevant literature on empirical assessment of different steps in conducting a multiples valuation methodology. The second section provides data and descriptive statistics. In the third section we state possible reasons for discrepancy between Russian and American market multiples values and argue in favor of adjustments. In the fourth section we describe and derive some major adjustments for country-risk. In the fifth section we present our methodology for country-risks corrections, whereas in the last section we assess their efficacy.

\section{Literature Review}

The empirical finance literature on comparables is focused on several major issues. Among the most popular lines of discussion one can find the analysis of relative weak and strong points of different valuation ratios. Baker M.R., Ruback R. [Baker M. R., Ruback R., 1999], Kim M., Ritter J.R. [Kim, M., Ritter J.R., 1999] show some advantages of ratios based on Earnings before Interest, Taxes, Depreciation and Amortization (EBITDA) over Enterprise Value-to-Sales (EV/S) or Enterprise Value-toEBIT (EV/EBIT). Liu J., Nissim D. and Thomas J. [Liu J., Nissim D., Thomas J., 2002] argue that despite the type of the industry Price-to-Earnings $(\mathrm{P} / \mathrm{E})$ ratio better fits valuations for many different industries. Lie E., Lie H. J. [Lie E., Lie H. J., 2002] show the types of ratios that better describe the valuation of the companies which differ in size. The research on fundamental factors affecting particular valuation multiples has a long history and is still under way. Zarowin P. [Zarowin P., 1990], Allen A.C., Cho Y., [Allen A.C., Cho Y., 1999] found out the critical influence of earnings growth rate in the forecasts on $\mathrm{P} / \mathrm{E}$, while historical growth rates and risks are not as much significant. Bhojraj S., C.M.C. Lee [Bhojraj S., C.M.C. Lee, 2002], Damodaran [Damodaran, 2004] underline another powerful set of independent variables: operating profit margin, business risk and growth measured by standard deviation of operating income and expected earnings growth rate. Boatsman J., Baskin E. [Boatsman J., Baskin E., 1981], Alford A.W. [Alford A.W., 1992], Bhojraj S., C.M.C. Lee [Bhojraj S., C.M.C. Lee, 2002], Herrmann V., Richter F. [Herrmann V., Richter F., 2003] proved that the fundamental factors affecting the ratios are more important for a comparable firm selection than the standard industry classification codes. Finally, there is a collection of papers on the discussion of adjustments for unsystematic risks (marketability discounts, size and control premiums).

The factors affecting valuation ratios in emerging markets have been tested by Oppong A. [Oppong A., 1993], Erb C.B., Harvey C.R., and Viskanta T.E. [Erb C.B., Harvey C.R., and Viskanta T.E., 1996], Nikbakht E., Polat C. [Nikbakht E., Polat C., 1998], Pereiro [Pereiro, 2002]. Damodaran [Damodaran, 2004] summarized his regression analysis with the conclusion about the influence of real GDP growth rates, low interest rates as independent variables to explain higher $\mathrm{P} / \mathrm{E}$ values. According to Ramcharran H. [Ramcharran H., 2002], P/E in 21 emerging markets is explained by economic growth and credit risk which he found to be statistically significant factors. Thus, it is clear that multiples drawn from different market environments depict different 
fundamentally justified values. That is why, methods for reducing such a discrepancy level in multiples values by using adjustment procedures are called for. However, despite many researchers acknowledge this fact, its justification remains an open issue.

\section{Data and descriptive statistics}

In this section we give a detailed statistical analysis of the multiples distributions properties in order to depict the cross-border difference in multiples values. We have chosen the Russian market as the emerging one and the U.S. as the developed. Our analysis is based on the annual data from 2001 to 2004 for both markets. For the U.S. market we have gathered the annual data from the Compustat Database provided by the FEDC: Database Environment. We selected all public traded companies domiciled in the United States at the NYSE, NASDAQ, and AMEX. Our sample companies matched the following criteria: the book value should be a positive measure, and the firm's profits should be positive for at least three out of four years. This restriction was imposed in order to assure a comparison with the Russian sample, which exhibits such characteristics. We excluded companies with unavailable Global Industry Classification Standard Code (GICS) ${ }^{19}$, or not classifiable. All items from the Balance Sheet and from the Income Statement were taken at the end of years 2001-2004 respectively. The share prices were taken four months after the fiscal year end, that is the closing price at the end of April for years 2002 to 2005. This common practice is often used by many researchers, since the four month lag ensures that the company has published its financial statements, and that they were available to investors, thus reflected in the share prices. The final sample consists of 15,104 firm-years observations.

For the Russian market we took data for all publicly traded firms on the Russian Trade System (RTS), RTS Board, Moscow Interbank Currency Exchange (MICEX), whose financial statements are reported in International Accounting Standards (IAS), or in United States Generally Accepted Accounting Principles (US GAAP). This was done in order to ensure comparability between data, because it is practically impossible to compare firms under the US GAAP and the Russian Accounting Principles, due to large difference in several key areas, such as depreciation accounting, good-will amortization, consolidated accounting etc. The same data were taken from the Balance Sheets and the Income Statement as for the American sample. We used the RosBusinessConsulting database for finding requested items, as well as the companies' statements posted on their websites. The majority of the firms didn't report negative earnings; however a limited number of companies reported losses, but not more than for one of the four considered years. The final sample constitutes 255 firm-years observation. However, it was necessary for the relative Russian firms to be similar to the US industry classification code. That is why we have linked the Russian companies to the 8-digit Sub-industry GICS code, since Russian companies do not have an approved classification scheme. The share prices were taken in the same way as for the American Market.

For these two markets we computed the following multiples:

- . $\mathrm{P} / \mathrm{B}$ ratio, defined as the market value of equity (total shares outstanding multiplied by the share price) divided by the book value of equity (or common shareholders equity, thus excluded preferred stocks).

- . $\mathrm{P} / \mathrm{E}$ ratio, defined as the market value of equity divided by the net income.

- EV/S, defined as the ratio of enterprise value to sales, where the enterprise value was defined as the market value of equity plus total debt (Long-term debt plus the

\footnotetext{
${ }^{19}$ The GICS classification methodology can be found at: http://www.mscibarra.com/products/gics/structure.jsp
} 
current portion of the long-term debt) plus preferred stock outstanding minus Cash and equivalents.

According to these definitions all multiples with undefined values were deleted from the sample; however, some negative multiples of unprofitable companies, which matched the criteria described above, were not deleted. Finally, for the U.S. market we have 12,709 P/B observations, 10,401 P/E observations, and 13,281 EV/S observations. Each multiple was winsorized for each year at $1 \%$ and $99 \%$. For the Russian market we computed $172 \mathrm{P} / \mathrm{B}$ multiples, $152 \mathrm{P} / \mathrm{E}$ multiples and $177 \mathrm{EV} / \mathrm{S}$ multiples. Table \#1 reports the descriptive statistics by countries for years 2001-2004.

Table \#1: Descriptive Statistics for Multiples

\begin{tabular}{|c|c|c|c|c|c|c|}
\hline \multicolumn{7}{|c|}{ U.S. Market } \\
\hline Multiple & \# obs. & Mean & Median & $\begin{array}{l}\text { Std. } \\
\text { dev. }\end{array}$ & Kurtosis & Skewness \\
\hline $\mathrm{P} / \mathrm{E}$ & 10,401 & 26.06 & 18.45 & 27.65 & 29.70 & 4.72 \\
\hline $\mathrm{P} / \mathrm{B}$ & 12,709 & 2.71 & 1.98 & 2.50 & 21.40 & 3.81 \\
\hline $\mathrm{EV} / \mathrm{S}$ & 13,281 & 2.67 & 1.73 & 2.63 & 3.57 & 1.79 \\
\hline
\end{tabular}

\begin{tabular}{|c|c|c|c|c|c|c|}
\hline \multicolumn{7}{|c|}{ Russian Market } \\
\hline Multiple & \# obs. & Mean & Median & dev. & Kurtosis & Skewness \\
\hline $\mathrm{P} / \mathrm{E}$ & 152 & 18.24 & 12.03 & 17.86 & 6.04 & 2.35 \\
\hline $\mathrm{P} / \mathrm{B}$ & 172 & 1.93 & 1.21 & 2.08 & 7.36 & 2.50 \\
\hline $\mathrm{EV} / \mathrm{S}$ & 177 & 1.75 & 1.22 & 1.51 & 5.78 & 2.26 \\
\hline
\end{tabular}

This table shows the comparison of multiples distribution across two countries. The U.S. market statistics is quite similar to precedent researches. For example, Maug E., Dittmann I. [Maug E., Dittmann I., 2006] report similar results the median for P/E equals - 17.01, for P/B - 1.87, for EV/S -1.63, taking into account that they have analyzed a broader sample from year 1994 to 2003. As usual all distributions are characterized by a high degree of skewness. The means substantially exceed the medians, especially for the $\mathrm{P} / \mathrm{E}$ multiple, which is true for the two markets. This is due to the outliers' property of skewing the representative mean toward the right tail. That is why, it is not advisable to use the arithmetic mean as an averaging procedure. The variability of the $\mathrm{P} / \mathrm{E}$ multiple is the biggest due to its dependency on profit. In order to reduce the estimates interval, it is advisable to use the P/B and EV/S multiples, which have the lowest standard deviation. The Kurtosis coefficient shows us, that all distributions have tails fatter than the normal distribution. From this viewpoint the EV/S seems to be a closer approximation, which is also confirmed by the lowest skewness coefficient. For the Russian market the same relationships hold. The $\mathrm{P} / \mathrm{E}$ multiple has the broadest variance, the mean exceeds the median, which means that the multiples are not uniformly distributed. The standard deviation for the $\mathrm{P} / \mathrm{E}$ multiple is the highest, for the other multiples it is much lower. The standard deviation of the $\mathrm{P} / \mathrm{B}$ and the EV/S multiples for the Russian market is pretty similar to those of the U.S., taking into account that the number of observations differs significantly.

Thus, it is clear, that the multiples values exhibit similar distribution patterns across the two markets, which confirms the possibility of making a comparative analysis between these two markets. However, it is important to point out, that table \#1 depicts 
the aggregated statistics for 4 years merged, both for the American and the Russian markets. Apart from this, it is necessary to understand how their properties evolved over time. For this purpose we perform a comparative analysis of Russian and American multiples distributions. Figure \#1 depicts the dynamical change of the P/E and P/B multiples distribution for the American market.

\section{Figure \#1: Distribution of the $\mathrm{P} / \mathrm{E}$ and $\mathrm{P} / \mathrm{B}$ multiples for the U.S. market for years 2002-2004}
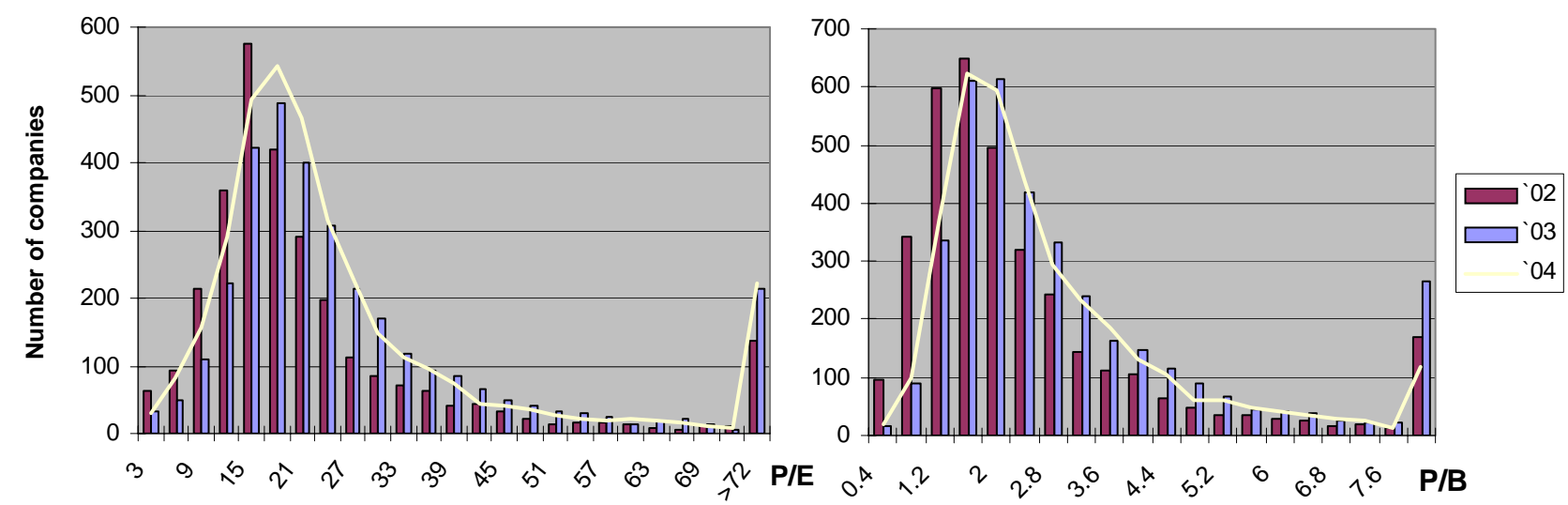

As we can see from the figure, the distribution of the multiples underwent significant changes for years 2002 to 2004. On the whole, we observe a stable asymmetry; however, in year 2002 the arithmetic mean and the median were shifted to the left. For example, the number of companies, having the P/E multiple lower than 18 and $\mathrm{P} / \mathrm{B}$ lower than 2, was significantly higher as compared to the subsequent years. For example, in year 2003 we observed the highest shift to the right, which pushed many companies from the left tail to the right. However, in year 2004 (depicted by a solid line) there was a small backward shift. But, on the other hand, we also observe an increase in the multiples values for companies lying within the standard deviation range from the median multiple value. Thus we can witness a general increase of the multiples values for the last three years.

The distribution of EV/S multiple depicted in appendix \#1 is characterized by lower variations. However, similar tendencies could be observed.

Thus, we can state that within the time period of 2002-2004 a significant swift of all multiples distributions took place, with a subsequent increase in the median values and an observable redistribution of companies from the left tail to the right.

Unfortunately, the conduction of a similar dynamical analysis for the Russian market is hampered, due to the lack of observations. However, we can make some important observations on aggregated data.

Figure \#2: Distribution of the $\mathrm{P} / \mathrm{E}$ and the $\mathrm{P} / \mathrm{B}$ multiples for the Russian market for years 2002-2004
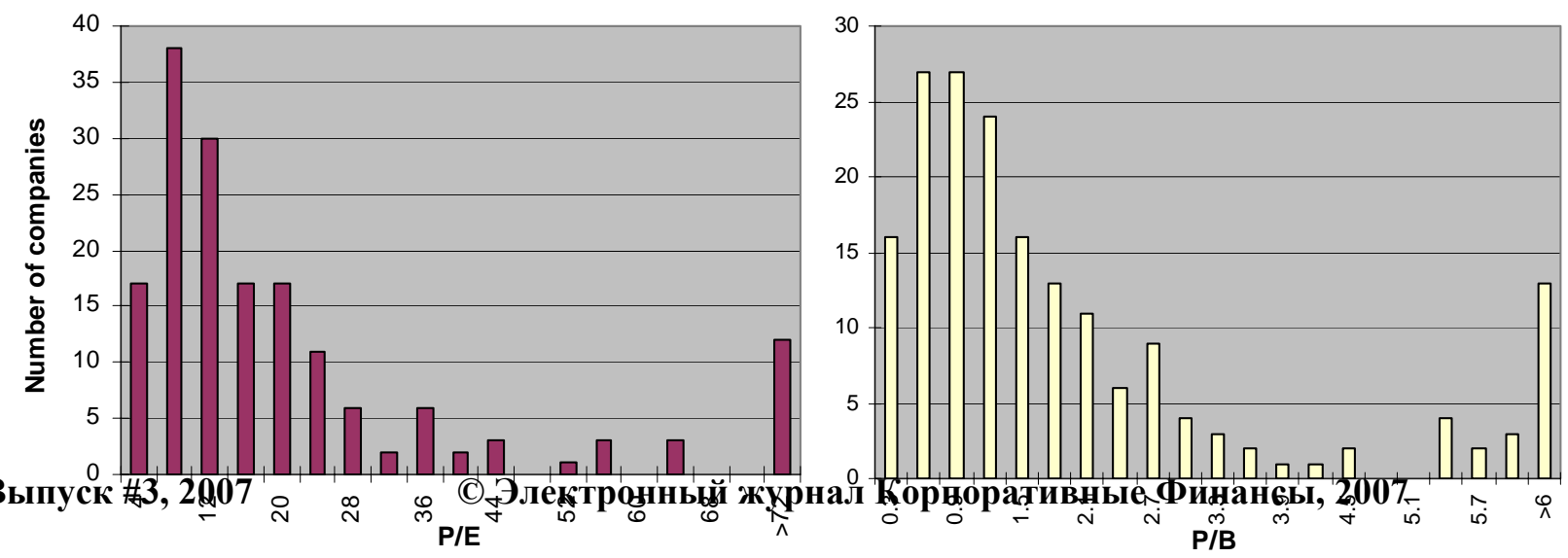
At a closer look at the $\mathrm{P} / \mathrm{B}$ and $\mathrm{P} / \mathrm{E}$ multiples distributions we found quite similar properties, as for the U.S. peers. The distributions are also skewed to the left, but the density of the $\mathrm{P} / \mathrm{E}$ distribution is thin compared to the $\mathrm{P} / \mathrm{B}$ multiple. The distribution of the EV/S multiple (Appendix \#2) is more symmetrical compared to the others. The skewness coefficient supports these specific findings. This is probably due to the fact that we didn't exclude companies with negative earnings, which lead to a creation of a more symmetrical distribution. Another interesting feature: the density of the distributions for these multiples differs significantly from the American peers. If for the latter we observe a smooth growth toward the median value, for the Russian ones - a sharp jump, i.e. the speed of reaching the median value is much higher.

After a detailed comparative analysis of the multiples distributions properties we found one important distinctive feature: as compared to the US distributions, the Russian distributions are characterized by a stronger left-sided shift. Moreover, a striking observation arises from the fact that the means and the medians for all the multiples are lower for the Russian market in comparison with the US (see table \#1). Thus, we have an obvious illustration that, on the whole, it is inaccurate to use the American multiples as it may lead to the overvaluation of Russian companies.

\section{Cross-border corrections rationale}

At first consideration the performed analysis reveals that the Russian companies are traded at discounted multiples due to the availability of hidden effects, which distort their fundamental values. Such effects could be a direct result of different economical states of affairs, financial, legal and regulating institutions. It is also related to the overall country risk level, which is born by the ineffectiveness or instability of the State machinery, by the weak protectability of investors' rights, and by a high degree of information asymmetry. These country risks become irrelevant if the investor has an opportunity to globally diversify its portfolio. However, 'if investors are constrained from entering or exiting specific country markets, they may find themselves isolated, or segmented, ... and come to bear country-related risk' [Pereiro, 2002, p.108]. It is obvious that such factors have a straightforward influence on the whole business environment, and more precisely on the investors' perception of assets values. Thus, by taking two identical companies, functioning on two different markets, we can assume that investors will value higher those, which will operate on the stable one, because its future development prospect will be brighter. At the same time the companies fundamentals can reach similar levels. 'Several empirical studies have clearly shown that this effect on stock return is frequently more sizable, than the industry effect. In other words, stock performance seems to be much more tightly linked to the local volatility of the economy, than to the fluctuations and trends of the corresponding industry at the international level" [Pereiro, 2002, p.109].

This problem can sometimes be extrapolated to the comparison of two developed markets; however, the difference in the magnitude of the above described effects will be smaller. It is known, that companies having similar expected growth rate of Net Income can have different P/E multiples. For example, American and Great Britain companies usually have a smaller P/E multiple, as compared to the German and Japanese ones. These differences are well illustrated by different researches analyzing the markets multiples relationships through different countries [Ramcharran H., 2002], [Damodaran, 2004], which show direct relationship between risk increase and lower market multiples values. Thus, ignoring the country risk in valuation can lead to significant overvaluation of companies operating on emerging markets, since their comparable counterparts will have completely different values due to a more stable economic state of affairs. Thus, the 
first effect which can explain the above stated discrepancy between Russian and American multiples could be the country risk.

Apart from the country risk, other hidden effects can sometimes influence the discrepancy between two companies' multiples levels. In the work by B. Black [B. Black, 2001] an interesting hypothesis is introduced: the differences in value between western companies and companies from emerging markets (or precisely the Russian ones) are a consequence of different Corporate Governance levels. The author departs from the point that 'the corporate governance behavior of the United States firms that affects their market value is scarce ... probably because the variation in such firm's behavior is small. ... The minimum quality of American corporate governance, set by law and by norms so widely accepted that almost no public firms depart from them, is quite high' [B. Black, 2001, p.1]. In contrast, the difference in the corporate governance level of Russian firms is very large, and has a measurable effect on the firm value. For this purpose the author examined 21 firms from the Russian market in year 1999, and found out that the correlation between the natural logarithm of the 'value ratio' (the ratio of actual market capitalization to the potential Western, computed by an independent Russian bank) strongly correlates with the governance ranking (determined independently by a second Russian investment bank). Thus, 'corporate governance behavior has a powerful effect on market value in a country where legal and cultural constraints on corporate behavior are weak' [B. Black, 2001, p.20]. That is why the second hidden effect can also have an influence on the difference between the multiples values of emerging and developed markets.

Thus, we observe that the combination of the two above mentioned effects explains to a certain extent the observed difference in market multiples. In order to reduce this overestimation of Russian companies, or precisely in order to reduce to a common denominator the American multiples values, we need to introduce some correction measures, which should be then incorporated into the valuation algorithm.

\section{Methods for multiples cross-border adjustments}

The use of several risk correction procedures plays a key role into the final company's value determination. This is especially true for unsystematic discounts and premiums which are often characterized by a high degree of subjectivity, which naturally lead to a high degree of uncertainty of the valuation outcome. Another problem arises with the use of some adjustments already computed by large financial agencies. The use of these numbers, without a clear understanding of their computation methodology could not be assumed satisfactory.

We examine cross-border adjustments based on three different approaches: the Spread of Sovereign Bonds Yield, the Correction Coefficient (Market Multiples Ratio) and Multiple Regression Approach for Country and Firm Specific Risks Corrections. The Market Multiples Ratio, as well as the regression methods have been already described by Pereiro [Pereiro, 2002], Damodaran [Damodaran, 2004] with the samples other than Russian companies. We add to the literature the third approach - Spread of Sovereign Bonds Yield method and examine the relative strength of all three methods to determine the most appropriate techniques. Let's consider them in detail.

\section{Spread of Sovereign Bonds Yield}

This method is often used by practical appraisers, who believe that the country risk is essential in determining the multiples values. In fact, this is a simple modification of the risk premium computed as an addition to the standard CAPM. The main idea of this correction is that there exists a positive relationship between the yield to maturity of a 
government bond and its default probability. The riskier the bond is, the higher return expects the investors. That is why the risk-free rate can be considered as a good proxy for market imperfections or country risk, or precisely the more the risk of the business environment, the less the investors' willingness to pay for a certain company, which will be reflected in smaller multiples values. The ratio between the US and Russian sovereign bonds yield could be seen as an adjustment for country risks.

As for the risk free US bonds we chose the US Treasury Notes with maturity period equal to five years at the end of April 2003-2005. For the Russian risk free government bonds, we have chosen the Russian Federation Minfin's Eurobonds, with maturity period equal to five years ${ }^{20}$. Taking into account that these two financial instruments are denominated in US dollars, the computed yield to maturity reflect only the relative country risk effect, without including other important firm-specific risks. Table \#2 provides the data on corresponding financial instruments at year 2004 (for years 2003 and 2002 look into the Appendix \#2).

Table \#2: Financial instruments at 29.04.05

\begin{tabular}{llrr}
$\begin{array}{c}\text { Name of the } \\
\text { Fin. } \\
\text { Instrument }\end{array}$ & $\begin{array}{c}\text { Maturity } \\
\text { Date }\end{array}$ & $\begin{array}{c}\text { Yield to } \\
\text { Maturity } \\
(\%)\end{array}$ & $\begin{array}{c}\text { Maturity } \\
\text { Term } \\
\text { (years) }\end{array}$ \\
\hline Euro-05 & 24.07 .2005 & 3.8 & 0.24 \\
Euro-07 & 26.06 .2007 & 4.7 & 2.16 \\
Euro-10 & 31.03 .2010 & 4.9 & 4.92 \\
Euro-18 & 24.07 .2018 & 6.2 & 13.24 \\
Euro-28 & 24.06 .2028 & 6.7 & 23.17 \\
Euro-30 & 31.03 .2030 & 6.2 & 24.94 \\
US TN-5 & 29.04 .2009 & 3.9 & 4.79 \\
\hline
\end{tabular}

However, before comparing the yield to maturity it is necessary to ensure that both instruments have same maturity terms, i.e. we need to find Russian Eurobonds with a maturity term equal to 5 years on 29 April 2003-05. For example, we can see from the table, that the best comparable instrument would be the EURO-10, but the difference still exists. Taking into account the term structure of the interest rates, it is worthwhile to assume that there is a cause-and-effect relationship between the expected spot rates and the maturity term of the Bonds, which has to have an increasing character. This is explained by the theory of unbiased expectations (the expected spot rate should be equal to the corresponding forward rate, i.e. the expected increase in the annual spot rate is a cause of the increase of the yield curve). Thus, by using a regression analysis we identified for each year a time relationship between the yield to maturity of the Eurobonds and its maturity term. For year 2005 this relationship is described by the following equation:

$$
\text { (1) } \quad Y T M=4.43+0.6 \ln T ; R^{2}=91 \% \text {. }
$$

Consequently, by inserting the corresponding maturity term of the US 5-years Treasury Notes we obtain a yield to maturity equal to 5.4\% for the Minfin's Eurobond. In Appendix \#5 other equations can be found. For each year we computed a theoretical yield to maturity for 5-years Eurobonds. The ratio between the US and the Russian yield to maturity is the sought correction coefficient, which only accounts for the country risk. Table \#6 presents the obtained results.

\footnotetext{
${ }^{20}$ The data for Minfin's Eurobonds were taken from the monthly reports of the Alfa-bank (see at www.alfabank.ru)
} 
Table \#3: Computation of Country Risk Corrections for years 2003-2005.

\begin{tabular}{|c|c|c|c|}
\hline Date of & \multicolumn{2}{|c|}{ Yield to Maturity } & Country Risk \\
\hline Valuation & Euro-5 & US TN-5 & Corrections \\
\hline 29.04 .2005 & 5.40 & 3.90 & 0.72 \\
\hline 29.04 .2004 & 5.51 & 3.65 & 0.66 \\
\hline 28.04 .2003 & 5.05 & 2.84 & 0.56 \\
\hline
\end{tabular}

From the table we can see that within the observed time period the relative Russian economy's risk decreased as compared to the American one, which lead to an increase in the correction value. Thus, in year 2005 the Russian multiples are approach their US peers, which is driven by the improving state of affairs of the Russian economy. In principle this is entirely corresponding to the observed situation. Let's turn ourselves to the next correction procedure.

\section{Market Multiples Ratio}

The second method introduced by L. Pereiro in his book 'Valuation of Companies in Emerging Markets' [Pereiro, 2002] consists in computing the ratio between two countries' market multiples. The idea is to find the relative value of one country's multiples in terms of the other (or how much 1 unit of the US multiple is worth in the emerging country's units). Thus we first calculate the means across the two markets' multiples at a specific date:

$$
\text { ratio }=\frac{\text { median }\left\{P / B_{r u s ; 2004}\right\}}{\text { median }\left\{P / B_{u s ; 2004}\right\}}
$$

This method depicts the relative difference between the investors' perceptions of the two markets and in principle describes the difference of country risks (firms, performing on a stable market, should have a higher multiples value). Basically, it is pretty similar to the last one, where we computed the theoretical market multiples ratio. However, it differs significantly since it already incorporates other firm-specific risks (such as the difference in the Corporate Governance level). That is why such correction should give better results as compared to the previous one. For each multiple we computed the corresponding correction at the end of April 2003-2005. Table \#4 depicts the results.

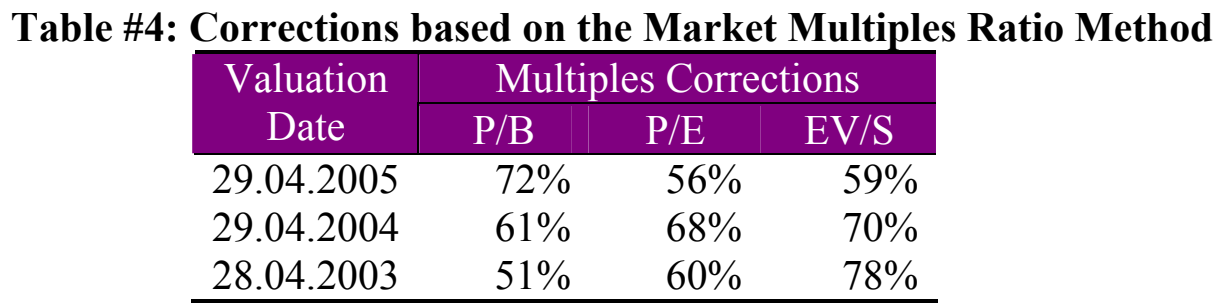

As we can see from the table, on the whole, the corrections stay at similar levels in comparison with the Spread of the Sovereign Bonds Yield Method. However, we can witness some peculiarities in the dynamical context. If for the $\mathrm{P} / \mathrm{B}$ multiple we can witness an increase in the corrections level (which means a decrease of the cross-border risks), for the $\mathrm{P} / \mathrm{E}$ multiple we observe a small drop in year 2005, and for the EV/S something completely different, a total decrease. The interpretation of these results is very intricate, since it is impossible to distinguish it from other effects. However, we can assume, that for the EV/S multiple the results could be worse as compared to the first correction method, since it doesn't trail the general economic pattern. On the other hand, we observe quite reasonable estimates, as for the previous method. But we should recall one crucial finding. Taking into account that we didn't take into consideration all Russian companies, or precisely those who reported their accounting in RAS (the Russian Accounting Standards) we expect to have lower median values of reported corrections on 
the whole Russian sample. This is linked to the fact, that those companies are mainly middle- and small-size firms, whose business doesn't have any international character, which probably means an increase of companies lying into the left tail of the multiples distribution.

\section{Multiple Regression Approach for Country and Firm Specific Risks Corrections}

At first sight the above proposed corrections are derived from the practical valuation viewpoint. In reality they could be subject to serious theoretical criticism. At the same time the fundamentally determined regression approach truly answers the question, whether cross-border corrections are required or not. The idea behind the regression method is quite simple: we run regression of multiples on their fundamentals parameters and on a dummy variable of the companies' home country. For the fundamentals we could use those, which reflect the return, risk and growth variables. The distinctive feature of this approach for country risk adjustments imply that the correction coefficients are predetermined by the model inputs, thus automatically laying down the magnitude of different hidden effects in the dummy coefficients estimates. If the dummy variable is significant - the coefficient should show the premium in the multiples value for companies from developed countries. The big advantage of this method is that it helps to objectively answer the question: are the cross-border effects really significant? If yes, then we assume that a combination of the above mentioned effects really influence the multiples values.

Taking into account the restricted dataset of Russian multiples, we considered the Chemicals, Telecommunications, Electric Utilities, Machinery, Metals \& Mining, and Oil \& Gas industries. Finally, it was possible to form an acceptable number of Russian and US companies, for the purpose of cross-border differences identification. For each multiple a single regression was run, which had its own explanatory variables, as the fundamentals variables and the general dummy variables. However, taking into account that the structural relationship between multiples and their fundamentals is time dependent, the use of the regression approach on the pooled data sample is inaccurate. For this reason we performed the analysis for each selected year. Let's look at this in detail:

- $\underline{P / B}$ multiple:

Based on previous researches, the current $R O E$ was chosen as the main fundamental variable, also an additional variable was introduced - the standard deviation of Net Income, which is considered to reflect the risk profile of the company. Taking into account that many previous researches deny the linear relationship between the $\mathrm{P} / \mathrm{B}$ multiple and the $R O E$, we used a log linear specification form, which in fact gave better results. We also took logs on standard deviation of the Net Income due to its high range; this helped us to scale its value. In order to identify the cross-border effects, a dummy variable for the company's country was introduced (for the US $=1$, for Russia $=0$ ). If the difference in cross-border effects really had a significant impact on the multiples values apart from the significance of this coefficient, we expected to find a positive sign, i.e. for the American company the premium value attributable to the absence of country risks should be a positive addition to the multiple value, and for the Russian one it should to be equal to 0 . We also used a dummy coefficient explaining industrial belonging of the firm. This is related to the fact that each industry has it own specific fundamentals values, whose difference should not be ignored. Let's consider the estimated models for year 2004 (the results for other years can be found in Appendix \#3). 
$\ln \left(\overline{P / B_{i}}\right)=0.8+0.33 \ln \left(R O E_{i}\right)-0.01 \ln \left(\sigma_{N_{i}}\right)+0.54 D_{\text {country }_{i}}+0.02 D_{\text {industry }_{i}} ; R^{2}=0.39$

$$
(0.168)
$$

The statistical relationship for the $\mathrm{P} / \mathrm{B}$ multiple is quite strong. The $\mathrm{R}^{2}$ of the model reach about $40 \%$ for all 3 years. Apart from this all coefficients have the expected sign: an increase of a company's ROE leads to an increase in the $\mathrm{P} / \mathrm{B}$ multiple value, the risk increase, expressed by the standard deviation of the Net Income variable reduces the P/B multiple. More important - the coefficient before the dummy variable is statistically significant and has a positive sign. Other things held constant, this means, that for a US company, the natural logarithm of the $\mathrm{P} / \mathrm{B}$ multiple will be 0.54 points higher as compared to the Russian one. The same results hold for the other years, however, the industry dummy variable is not always statistically significant. At the aggregated level the $\mathrm{R}^{2}$ falls to $30 \%$, but all conclusions are still the same and the coefficients estimates are statistically significant.

\section{- P/E multiple:}

For the explanatory variable of the P/E multiple we used the expected growth rate of the Net Income variable, and an additional risk measure - the standard deviation of the Net Income. As in the case of P/B multiple, we assumed a log linear specification form. However, taking into account, that it is impossible to compute the logarithm of the negative growth rate of the Net Income, we didn't impose a logarization on this variable. The estimated regression model for the P/E multiple in the year 2003 looks like:

$$
\ln \left(\overline{P / E_{i}}\right)=2.57+0.08 N I_{\text {growth }_{i}}-0.02 \ln \left(\sigma_{N I_{i}}\right)+0.24 D_{\text {country }_{i}}-0.01 D_{\text {industry }_{i}} ; R^{2}=0.1
$$

As we can see all coefficients' estimates are significant, apart from the industrial dummy variable. Moreover, the expected magnitude of all coefficients is preserved: with an increase in the future Net Income growth rate increases the P/E multiple's value, the risk increase of the company leads to the reduction of its value. Once more the country's dummy variable coefficient is statistically significant and has an expected sign, thus the American companies are traded with a premium compared to the Russian ones, which take the form of higher multiples value. However, for year 2004 we observe a statistical insignificance of the fundamental variable and an unexpected negative sign. Such results should not be surprising, since the projected value of the Net Income variable for year 2005 , was taken as the future regression-averaged value, which in principle is a poor substitute for the market's expectations. On aggregated level, all coefficients are statistically significant, and the $\mathrm{R}^{2}$ increases to $15 \%$. Thus, we can state that the difference in cross-border effects really affects the multiples values.

\section{- EV/S multiple:}

For this multiple the Operating Margin was chosen as the main fundamental variable, and for the risk variable we choose the standard deviation of the EBIT. Compared to the previous cases, we didn't assume a log linear specification form, however in order to scale the standard deviation we used a logarization of this variable, i.e. that an additional contribution of the marginal increase of this variable has a decreasing influence on the overall multiple increase.

For the EV/S multiple we observe the most robust estimates. The $\mathrm{R}^{2}$ of the model fluctuates around $40 \%$, whereas all coefficients (including the industrial dummy 
variable) for the three years are statistically significant. For year 2004 the regression model looks like:

$$
E V / S_{i}=1.26+2.85 \cdot O M_{i}+0.08 \ln \left(\sigma_{E B I T_{i}}\right)+0.42 D_{\text {country }_{i}}-0.22 D_{\text {industry }_{i}} ; R^{2}=0.26
$$

All variables, except for the company's risk, have expected signs. As to the previous cases, the country dummy variable is still significant, this once more proves the necessity of using some cross-border corrections.

Thus, we described in detail used country risks corrections. However, in order to interpret the efficacy and the necessity of such cross-border corrections, we should, first, perform their empirical testing. Let's consider in detail the empirical model for crossborder corrections.

\section{The empirical mode for cross-border corrections: underlying principles}

The most effective way to determine the best used methods is an empirical checkup based on a large database, which means that we first analyze different companies' valuation methodologies, and then judge about their relative efficacy based on the deviation degree of projected company's value from the observed one by the market. Thus, we automatically assume the efficient market hypothesis, by agreeing that the market value of a company is a fair estimate.

In order to assess three country risk correction methodologies, we constructed two fundamentally different valuation algorithms: the algorithm of relative corrections (where we focus on the efficiency of the Spread of Sovereign Bonds Yield, and Market Multiples Ratio methods), and the algorithm of the regression approach for country and firm-specific risks corrections. Let's consider them in detail.

\section{Algorithm of relative corrections' efficiency analysis}

Based on the recent empirical researches, we observed that the best method of comparables companies' selection could be the method based on similar fundamentals parameters identifications, which can in principle ignore the companies' industrial classification. On the one hand, the same industrial belonging means that comparable companies are faced with similar industrial risks and comparable environmental conditions; on the other hand, the majority of companies have their own exceptional attributes, whose identification can give better understanding of the current business state, than the industrial classification. In view of these reasoning, we take as a basis three companies selection algorithms:

- Industrial Classification Method

For the filter criteria based on industrial belonging we used the 6-digits GICS code (last degree of industrial specification). Thus American companies, having the same GICS code as the Russian company, were selected into the comparables companies' dataset. Such high degree of specification ensures that companies should be subject to similar industrial factors, influencing the firm's value.

- Fundamentals' Filter Method

For this method we chose for each multiple a pre-specified parameter:

1) for $\mathrm{P} / \mathrm{B}$ multiple - current return on equity (ROE)

2) for $\mathrm{P} / \mathrm{E}$ multiple - future deviation of net income from its current state or simply the future growth rate of Net Income variable (NI growth), which is a good substitute for its expected value 
3) for EV/S multiple - current operating margin (OM).

For selecting a potential comparable we assign a specific deviation interval from the Russian company's fundamentals value, if the potential comparable company fundamental lies within this interval - we select it as a comparable company. For the $R O E$ we assigned a $10 \%$ deviation interval, i.e. if the Russian company has a $R O E=25 \%$, the comparables companies are those, whose $R O E$ is less than $35 \%$ and more than $15 \%$. For the NI growth - 30\%, since this variable has a very large dispersion both for the Russian and American markets. For the $O M-10 \%$. It is interesting to know, that the increase in the interval values leads to a significant reduction of the valuation accuracy, which is probably related to the fact, that we selected secondary companies.

- Combination of these two, which assumes a primary filtering on industrial belonging, and a secondary - on similar fundamentals.

For the last method of comparables' selection (the combined method of the last two), an industry code filter is first applied, and then continued with a selection, based on a fundamental parameter. Taking into account, that after the first filter the obtained dataset of comparables companies was significantly reduced, we increased the intervals' range in order to ensure that any companies would be identified in the $\mathrm{P} / \mathrm{B}$ Set \#3. For the ROE $-25 \%$, NI growth $-60 \%$ and for $\mathrm{OM}-30 \%$. It is interesting to state, that compared to previous researches our intervals are significantly narrow. Herrmann V., Richter F., [Herrmann V., Richter F., 2003] use for the fundamentals filter values of 30\% for ROE and NI growth, and for the combined method $-50 \%$. That is why we expect to have better results for this method compared to the simple industry classification, whereas the efficacy of the fundamentals method is difficult to assess.

For the valuation purposes we used 3 common multiples: $\mathrm{P} / \mathrm{B}, \mathrm{P} / \mathrm{E}$ и $\mathrm{EV} / \mathrm{S}$, where the initial dataset was the American and Russian companies data, described in the previous section. For the valuation of 255 Russian companies-years with the use of 15,104 American companies-years, with a combination of all possible valuation methods reaching 27 (precise multiple $\Rightarrow$ precise selection criteria $\Rightarrow$ precise correction procedure) we build a simulated valuation routine in the Ox edit core (based on Gauss programming language), which helped us to mix all possible combinations and provide a summary statistics, assessing their overall performance.

Scheme \#1 depicts the general sequence of the programmed valuation algorithm for the $\mathrm{P} / \mathrm{B}$ multiple, for a specific year. 


\section{Scheme №1: Valuation Algorithm for P/B Multiple}

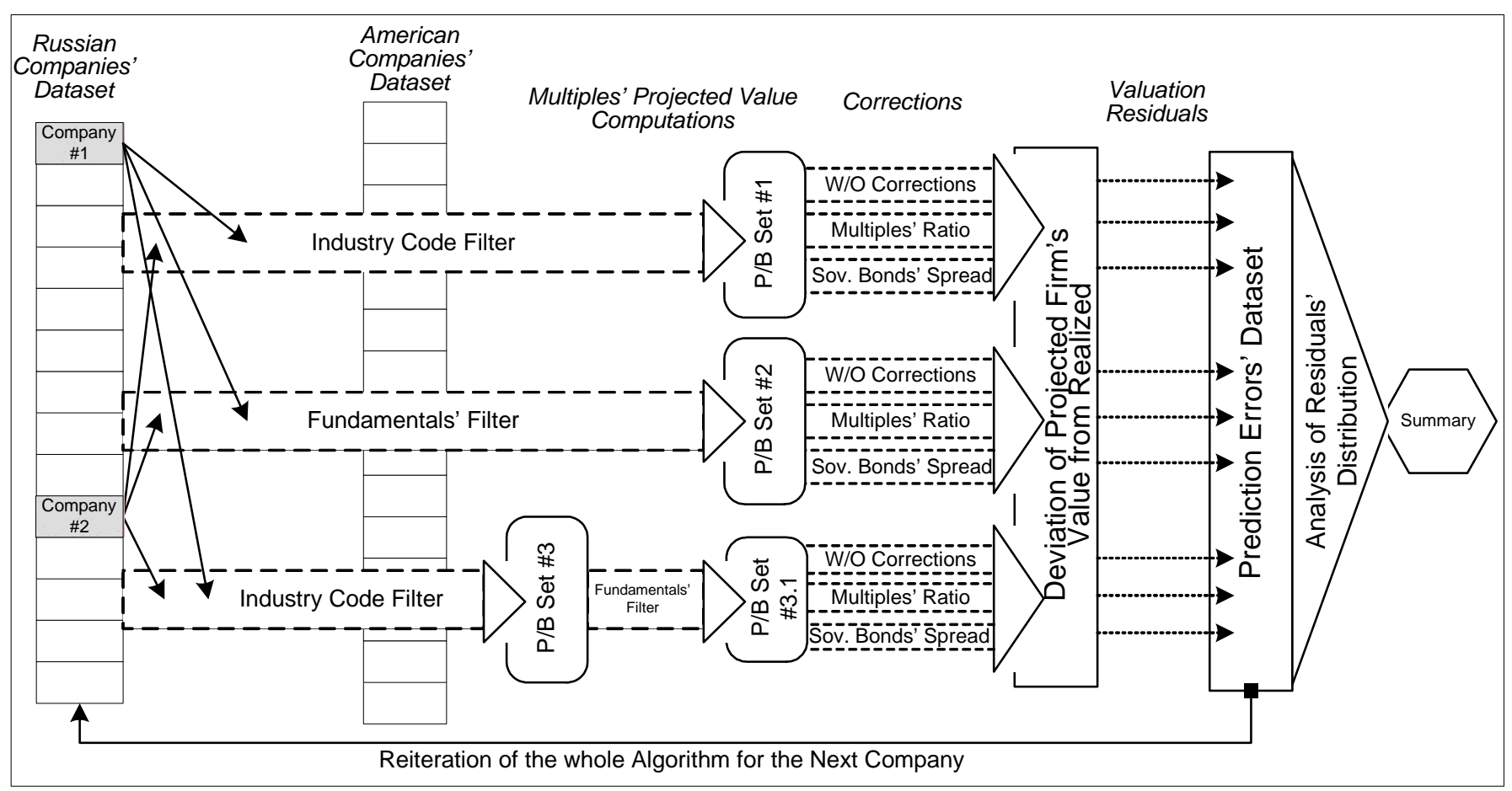

The valuation algorithm begins from taking the first company from the Russian Companies Dataset (or more precisely its financial and industrial information) and then performs a valuation based on all possible combinations of methods, only for this first Russian company. However, before performing a valuation, we need to cast aside a certain amount of American outliers. In order to get objectively justified values, we winsorize the sample by $1-5 \%$ (depending on the multiple) for each year.

Thus from the first step the valuation methodology goes into three different directions. From the American sample, the algorithm filters those companies which satisfy the imposed criteria for each filter used. After this step the algorithm computes the synthetic multiple's value for each comparables selection method used. For this purpose we use the simple median measure, as it is the most convenient way to deal with the problem of reducing the influence of outliers on the overall firm's value.

On the next stage, we use three different correction procedures for each multiple: without any correction, with the Spread of Sovereign Bonds Yield method, and with the Market Multiples Ratio. We expect that without any correction the valuation accuracy will be the worst, due to the availability of certain country and firm's specific risk differences between companies. After computing the correctorized multiple's value, we assess the overall accuracy of the used methods. For this purpose we analyze the deviation of the projected firm's value from it's realized on the Russian market. For each Russian company we computed the corresponding residuals (for each combination of methods used), which are depicted by dotted arrows. Thus for company \#1 we get 9 residuals (only for the $\mathrm{P} / \mathrm{B}$ multiple), which are then registered into the valuation's residuals database. After that the program automatically returns to the first step and repeats the whole algorithm for the next company. It is necessary to point out, that for each multiple the valuation is performed at precise dates, i.e. for year 2002 we use the American Companies' Dataset at year 2002 and so on.

After we computed the residuals values for all Russian companies, the algorithm begins to analyze the distribution of all residuals for each combination of methods (i.e. for the P/B multiple - 9). On computed statistics' basis we draw conclusions about the 
relative efficacy of the selection of comparable companies' criteria, and on the correction procedure.

It is noteworthy to point out, that the regression approach of country and firm specific risks corrections has a totally different algorithm, that is why the analysis of its effectiveness is conducted separately (also for each multiple). Let's now consider in detail the main assumptions and preconditions laid in each step of the above described algorithm.

\section{Algorithm of the regression approach in cross-border corrections}

We should take into account the fact that the multiple regression approach has a quite different algorithm compared to scheme \#1. At the first step we not only analyze the dataset the Russian companies, but the pooled sample in precise year, where the American companies are identified with a dummy variable. Taking into account the outliers' problem we winsorized the sample on 1 and $99 \%$, in order to eliminate extreme values, which were capable to disturb the coefficient's significance. A regression was then run for each multiple on the fundamental value and on the dummy coefficient. After we got our coefficients' estimates for each multiple, we built a theoretical valuation model for valuing only Russian firms. As in the previous case, we then computed the projected firm's value and compared it with the realized one, thus getting our valuation residuals, which were then included into the predictions errors' dataset. Taking into account that the multiples regression relationships suffer from time variability, the use of a regression analysis on aggregated dataset for years 2002-2004 is not reasonable. That is why the algorithm repeats the whole procedure for the next year.

Thus, we described in detail the general principles and assumptions of the used empirical simulated valuation model. Let's consider now the final efficacy of the above described corrections for cross-border effects.

\section{Empirical analysis of cross-border corrections' efficiency}

\section{Effectiveness of Relative Corrections Procedures}

As we have seen from scheme \#1, the algorithm initially uses 3 different selection criteria for comparable companies. We first, choose the two best out of the three selection procedures, and then based on them, compare the relative efficacy of the depicted corrections. For each multiple we computed specific efficiency criteria, assessing the projected company's value with the current realized state. Thus, we use 4 criteria measuring correction efficiency: a simple arithmetic mean of the predictions errors, median of the predictions errors, median of the absolute predictions errors, root mean squared errors (RMSE). The advantage of using the median criterion over the simple average consists in the fact that they effectively solve the outliers problem, but the question of counting the standard deviation is still open. The advantage of the RMSE consists of accounting for the bias, and the standard deviation of the errors at the same time. This measure is effectively used by Maug E., Dittmann I. [Maug E., Dittmann I., 2006]. Thus, this variable is the most objective in the overall efficacy assessment of the employed valuation algorithm, however, at the same time it gives no clear indication whether we have under- or overvalued our companies. Table \#5 depicts the obtained results. 
Table \#5: Comparative Efficacy of Comparable Companies' Selection Criteria

\begin{tabular}{l|rr|rrr|}
\hline \multirow{2}{*}{ Filter Method } & \multicolumn{5}{c|}{ P/B Multiple } \\
\cline { 2 - 6 } & Mean & Median & Abs. Median & RMSE & Std. dev \\
\hline Industry Code & $108 \%$ & $57 \%$ & $76 \%$ & 2.25 & 1.98 \\
Fundamentals & $103 \%$ & $71 \%$ & $79 \%$ & $\mathbf{1 . 8 8}$ & 1.58 \\
Industry Code+Fundamentals & $87 \%$ & $47 \%$ & $77 \%$ & $\mathbf{1 . 9 7}$ & 1.77 \\
\hline
\end{tabular}

\begin{tabular}{|l|r|r|rr|c}
\hline \multirow{2}{*}{ Filter Method } & \multicolumn{5}{c}{ P/E Multiple } \\
\cline { 2 - 6 } \multicolumn{1}{c|}{} & Mean & Median & Abs. Median & RMSE & Std. dev \\
\hline Industry Code & $62 \%$ & $38 \%$ & $68 \%$ & $\mathbf{1 . 5 1}$ & 1.38 \\
Fundamentals & $90 \%$ & $41 \%$ & $\mathbf{6 4 \%}$ & 1.85 & 1.62 \\
Industry Code+Fundamentals & $59 \%$ & $31 \%$ & $\underline{\mathbf{6 3 \%}}$ & $\underline{\mathbf{1 . 4 9}}$ & 1.38 \\
\hline
\end{tabular}

\begin{tabular}{l|r|r|rr|c}
\hline \multicolumn{1}{c|}{ Filter Method } & \multicolumn{5}{c|}{ EV/S Multiple } \\
\cline { 2 - 6 } \multicolumn{1}{c|}{ Mean } & Median & Abs. Median & RMSE & Std. dev \\
\hline Industry Code & $67 \%$ & $32 \%$ & $63 \%$ & 1.48 & 1.33 \\
Fundamentals & $74 \%$ & $38 \%$ & $\underline{\mathbf{5 0 \%}}$ & $\underline{\mathbf{1 . 4 2}}$ & 1.21 \\
Industry Code+Fundamentals & $65 \%$ & $26 \%$ & $\mathbf{5 6 \%}$ & $\mathbf{1 . 4 5}$ & 1.30 \\
\hline
\end{tabular}

This table focuses only on the efficacy of comparable companies' selection criteria, without imposing any correction procedure. As we can see from the table, the simple arithmetic mean of the predictions errors is practically always higher, compared to the median. The simple median for each multiple is higher than 0 , independently on the selection criterion. In fact this is another confirmation that ignoring the cross-border effects will lead to serious overvaluation of the companies operating on an emerging market. The depicted results prove objectively this fact. Thus, based on the simple median, we can conclude that with all possible selection criteria the average prediction error (or overvaluation) fluctuates into the range of $30-60 \%$, which is not satisfactory.

It is better to compare the relative efficacy of the methods by combining the absolute median (or more precisely the median of the absolute predictions errors) with the RMSE. In this table we marked in italics and stressed the best possibility, the secondbest is written in thick print. For the P/B multiple the best results are showed by the combined method (industry code and fundamentals' selection criterion), the worst is the industry classification method, whose RMSE is equal to 2.25 , which is also proved by the highest dispersion. Thus, from the viewpoint of the RMSE the preferences should be unambiguously given to the last two methods of comparables companies' selection. From the viewpoint of the absolute median, all methods give practically same bad results - in average the incorrect projected value deviates from the realized one by $76-79 \%$. As a result we give preference to the last two comparable companies' selection criteria.

For the $\mathrm{P} / \mathrm{E}$ multiple the overvaluation is slightly smaller, however, stays at the level of $30-40 \%$, which is confirmed by the simple median. On the other hand, the combined selection method is unambiguously the leader, whose RMSE and absolute median reach 1.49 and $63 \%$ respectively. As to the other two methods, it is difficult to give preference to any of them, since the RMSE is higher for the industrial classification method, but the absolute median - for the fundamentals method. On the other hand, such results are probably driven by the fact, that for year 2004 the fundamental of the P/E multiple was the regressed projected value of Net Income growth rate for year 2005, which significantly worsened the statistics (remember the statistical insignificance of this variable for year 2005 and its 'incorrect' sign showed in the last section). That is why such large standard deviation is probably due to the inefficacy of this projected value, rather than to the low self-descriptiveness of the variable itself. In spite of this fact, the efficacy of this method stays at the same level as for the combined method: in average 
the incorrect predicted company's value deviates from its realized one by $64 \%$. In spite of the fact, that the observed results are also not satisfactory, the overall valuation accuracy is better compared to the $\mathrm{P} / \mathrm{B}$ multiple, but the overvaluation problem still remains.

The valuation based on the EV/S multiple gives slightly better results compared to the previous multiples, but the same problems remain. First, we observe an evident overvaluation of all companies within the range of $26-38 \%$, second, $55 \%$ in terms of the absolute median is really not satisfactory. As for the comparables companies' selection procedure the absolute leader is the second fundamentals method, followed by the combined one. The industrial classification gives the worst results; this is especially captured by the absolute median whose value exceeds by $13 \%$ the fundamentals method. Thus, we can make the final conclusions about the best methods of comparable companies' selection. As we expected, the combined method and the method based on similar fundamentals parameters selection give better results than the simple industrial classification. For the P/B and the EV/S the fundamentals method is the leader, for the $\mathrm{P} / \mathrm{E}$ - the combined one.

Now from, on the basis of these conclusions, we can proceed to the efficacy analysis of the relative corrections for cross-border effects. Table \#6 presents the results of these two methods for the P/B multiple.

Table \#6: Comparison of the Relative Corrections' Efficacy for the P/B Multiple

\begin{tabular}{l|rrrrr}
\hline \multicolumn{1}{c|}{$\begin{array}{c}\text { Correction } \\
\text { procedure }\end{array}$} & Mean & Median & Abs. Median & RMSE & Std. dev \\
\hline W/O Corrections & $103 \%$ & $71 \%$ & $79 \%$ & 1.88 & 1.58 \\
Sov. Bonds Spread & $31 \%$ & $14 \%$ & $48 \%$ & 1.01 & 0.97 \\
Multiples Ratio & $24 \%$ & $9 \%$ & $\mathbf{4 7 \%}$ & $\mathbf{0 . 9 4}$ & 0.91 \\
\hline
\end{tabular}

\begin{tabular}{l|rrrrr}
\hline \multicolumn{1}{c|}{$\begin{array}{c}\text { Correction } \\
\text { procedure }\end{array}$} & \multicolumn{5}{|c}{ Industry Code and Fundamentals' Filter Method } \\
\cline { 2 - 6 } & Median & Abs. Median & RMSE & Std. dev \\
\hline W/O Corrections & $87 \%$ & $47 \%$ & $77 \%$ & 1.97 & 1.77 \\
Sov. Bonds Spread & $20 \%$ & $-1 \%$ & $51 \%$ & 1.07 & 1.06 \\
Multiples Ratio & $13 \%$ & $-6 \%$ & $\mathbf{5 0 \%}$ & $\mathbf{0 . 9 9}$ & 0.98 \\
\hline
\end{tabular}

As we can see from the table, the use of corrections procedures dramatically changed the picture. Even in the case of the simple arithmetic mean we observe a significant drop of prediction errors from $103 \%$ to $24 \%$ for the first method (comparable companies' selection based on fundamentals' filter method), and from $87 \%$ to $13 \%$ for the second one (the combined method). Based on the simple median, we also observe some significant shifts. For the first method the average overvaluation falls to $9-14 \%$ for the two used correction methods, compared to the case of disusing these methods (71\%). For the second comparables companies selection method we practically observe a null average percentage deviation of the projected value from the realized one.

The Market Multiples Ratio gives slightly better results compared to the Spread of Sovereign Bonds Yield method. If on average the deviation of the projected value from its realized state stays at the comparable level for each selection method (48-47\%; 51$50 \%$ ), the RMSE points out the advantage of the Market Multiples Ratio method. Let's consider now the results for the $\mathrm{P} / \mathrm{E}$ multiple. 
Table \#7: Comparison of the Relative Corrections' Efficacy for the P/E Multiple

\begin{tabular}{l|rrrrr}
\hline \multirow{2}{*}{$\begin{array}{l}\text { Correction } \\
\text { procedure }\end{array}$} & \multicolumn{5}{|c|}{ Fundamentals Filter Method } \\
\cline { 2 - 6 } & Mean & Median & Abs. Median & RMSE & Std. dev \\
\hline W/O Corrections & $90 \%$ & $41 \%$ & $64 \%$ & 1.85 & 1.62 \\
Sov. Bonds Spread & $26 \%$ & $-11 \%$ & $\mathbf{5 1 \%}$ & 1.13 & 1.11 \\
Multiples Ratio & $15 \%$ & $-12 \%$ & $54 \%$ & $\mathbf{1 . 0 0}$ & 0.99 \\
\hline
\end{tabular}

\begin{tabular}{l|rrrrr}
\hline \multirow{2}{*}{$\begin{array}{l}\text { Correction } \\
\text { procedure }\end{array}$} & \multicolumn{4}{|c}{ Industry Code and Fundamentals Filter Method } \\
\cline { 2 - 6 } & Mean & Median & Abs. Median & RMSE & Std. dev \\
\hline W/O Corrections & $59 \%$ & $31 \%$ & $63 \%$ & 1.49 & 1.38 \\
Sov. Bonds Spread & $4 \%$ & $-16 \%$ & $53 \%$ & 0.92 & 0.92 \\
Multiples Ratio & $-4 \%$ & $-19 \%$ & $\underline{\mathbf{5 1 \%}}$ & $\underline{\mathbf{0 . 8 1}}$ & 0.82 \\
\hline
\end{tabular}

As with the case of the $\mathrm{P} / \mathrm{B}$ multiple, we observe a significant improvement achieved by using corrections for country and firm-specific risks. Moreover, even the simple arithmetic mean gives quite reasonable estimates for the second selection method. However, for these corrections we observe an understatement of the Russian companies, which is reflected into the negative value of the simple median measure. For the Market Multiples Ratio the understatement is even higher than for the Spread of Sovereign Bonds Yield method.

For the first selection method, based on the RMSE, the preferences are given to the second correction method, even in spite of a small discrepancy in the absolute median's values. In case of using the combined method of companies' selection the Market Multiples Ratio is the absolute leader, since the RMSE and the absolute median values are lower. It is interesting to point out that even after corrections implementations the second method of comparables companies' selection still prevails, as in the case of any corrections disuse.

Table \#8 depicts the results on the last considered multiple $-E V / S$. As in the previous cases, the use of cross-border corrections affect significantly the conclusions:

Table \#8: Comparison of the Relative Corrections' Efficacy for the EV/S Multiple

\begin{tabular}{|c|c|c|c|c|c|}
\hline \multirow{2}{*}{$\begin{array}{l}\text { Correction } \\
\text { procedure }\end{array}$} & \multicolumn{5}{|c|}{ Fundamentals Filter Method } \\
\hline & Mean & Median & Abs. Median & RMSE & Std. dev \\
\hline $\begin{array}{l}\text { W/O Corrections } \\
\text { Sov. Bonds }\end{array}$ & $74 \%$ & $38 \%$ & $50 \%$ & 1.42 & 1.21 \\
\hline Spread & $15 \%$ & $-9 \%$ & $42 \%$ & 0.84 & 0.83 \\
\hline Multiples Ratio & $18 \%$ & $-8 \%$ & $\overline{48 \%}$ & 0.82 & 0.80 \\
\hline
\end{tabular}

\begin{tabular}{l|rrrrr}
\hline \multicolumn{1}{c}{$\begin{array}{c}\text { Correction } \\
\text { procedure }\end{array}$} & \multicolumn{5}{c}{ Industry Code and Fundamentals Filter Method } \\
\cline { 2 - 6 } & Mean & Median & Abs. Median & RMSE & Std. dev \\
\hline W/O Corrections & $65 \%$ & $26 \%$ & $56 \%$ & 1.45 & 1.30 \\
Sov. Bonds & & & & & \\
Spread & $8 \%$ & $-15 \%$ & $\underline{\mathbf{4 6 \%}}$ & $\underline{\mathbf{0 . 8 6}}$ & 0.85 \\
Multiples Ratio & $12 \%$ & $-18 \%$ & $\underline{51 \%}$ & 0.91 & 0.90 \\
\hline
\end{tabular}

For each selection method we observe a significant decrease in the RMSE variable. However, we once more fall into the problem of Russian companies' undervaluation, judging by the simple median measure. Overall, the use of cross-border corrections does not affect the advantage of the first selection method. Concerning the relative efficacy of the corrections, we can observe a small preference toward the Spread of Sovereign Bonds Yield method, judging by the absolute median criterion, whereas the RMSE stays at a similar level. For the second selection method the Spread of Sovereign Bonds Yield 
correction method gives explicitly better results. We assume that the advantages of this method are due to the inexplicable dynamics of the EV/S correction coefficient, compared to those of the Spread of Sovereign Bonds Yield correction coefficient, which is objectively linked to the reduction of the relative Russian country risk.

Thus, we have found out, that the use of relative cross-border corrections really improves the valuation accuracy, reducing the average prediction errors. For the $\mathrm{P} / \mathrm{B}$ and $\mathrm{P} / \mathrm{E}$ multiples the Market Multiples Ratio gives better estimates, whereas for the EV/S the Spread of Sovereign Bonds Yield method. Let's consider the last correction method for cross-border corrections.

\section{Effectiveness of the Regression Approach in Cross-border Corrections: Conclusive Finding}

As we have already stated, the regression approach is used for assessing the correction necessity, as well as giving another more reliable company's value estimation. However, we once more point out, that the initial pooled dataset is much smaller compared to the one analyzed into the previous section, due to the lack of Russian companies within some specific industries. The next table gives the overall regression approach performance for three analyzed multiples:

Table \#9: Regression Approach in Cross-border Corrections

\begin{tabular}{l|rrrrr}
\hline \multirow{2}{*}{ Multiples } & \multicolumn{5}{c|}{ Regression approach } \\
\cline { 2 - 6 } & Mean & Median & Abs. Median & RMSE & Std. dev \\
\hline P/B & $17 \%$ & $4 \%$ & $32 \%$ & 0.69 & 0.67 \\
$\mathrm{P} / \mathrm{E}$ & $5 \%$ & $-8 \%$ & $46 \%$ & 0.76 & 0.76 \\
$\mathrm{EV} / \mathrm{S}$ & $6 \%$ & $1 \%$ & $35 \%$ & 0.67 & 0.67 \\
\hline
\end{tabular}

From the table a straightforward observation arises: this method gives much better estimates for each analyzed multiple. First of all, the simple median fluctuates around zero, which means that on average we have succeeded in finding the right company value. However, such conclusion doesn't have any serious implication, since we could have an unacceptably high dispersion of the errors' predictions. The RMSE fluctuates around $70 \%$ for each multiple, which is much smaller compared to the previous cases. The absolute median also showed better off the analyzed method. For the P/B and EV/S multiples the absolute predictions errors are ranged from $32-35 \%$, however for the $\mathrm{P} / \mathrm{E}$ the estimates are poorer in terms of the absolute median and RMSE. This is probably driven by the fact, that we haven't found a more reliable substitute for the expected growth rate of the Net Income variable.

Comparing the results of this method with those of the previous section would be inappropriate, since we ran our regressions on a totally different dataset. For this purpose we repeated the whole analysis for the relative corrections procedure at the same restricted dataset. The statistics can be found in Appendix \#7. The restriction of the dataset didn't affect in any way the previous conclusions. For the $\mathrm{P} / \mathrm{B}$ and $\mathrm{EV} / \mathrm{S}$ multiples the best comparables companies selection method is the fundamentals filter and the combined method better performs for the P/E multiple. The same results hold for the correction used: for the $\mathrm{P} / \mathrm{B}$ and $\mathrm{P} / \mathrm{E}$ the Market Multiples Ratio gives significantly better estimates compared to the Spread of Sovereign Bonds Yield method. For the EV/S multiple the effectiveness of the Spread of Sovereign Bonds Yield correction is slightly better, compared to the previous method.

In spite of the fact, that we have restricted our sample, the presented statistics is still approximately the same compared to those presented on the whole sample, only for the P/B multiple the Market Multiples Ratio gives a significantly better absolute median 
mean of the predictions errors, for each selection method used: $33 \%$ versus $54 \%$ (for the industrial classification method) and $40 \%$ versus $51 \%$ (for the combined).

Now we are ready to perform the final comparison of the corrections methodologies. For this purpose we present a graphical illustration of the median of the absolute pricing errors, which in principle is closely related to the RMSE measure. Figure \#3 depicts the efficacy of the relative corrections based on the best selection criterion (for the $\mathrm{P} / \mathrm{B}$ and $\mathrm{EV} / \mathrm{S}$ it is the fundamentals method, for the $\mathrm{P} / \mathrm{E}$ - the combined) compared to the regression approach.

Figure \#3: Comparison of the Median of Absolute Predictions Errors (for Best Selection Method)

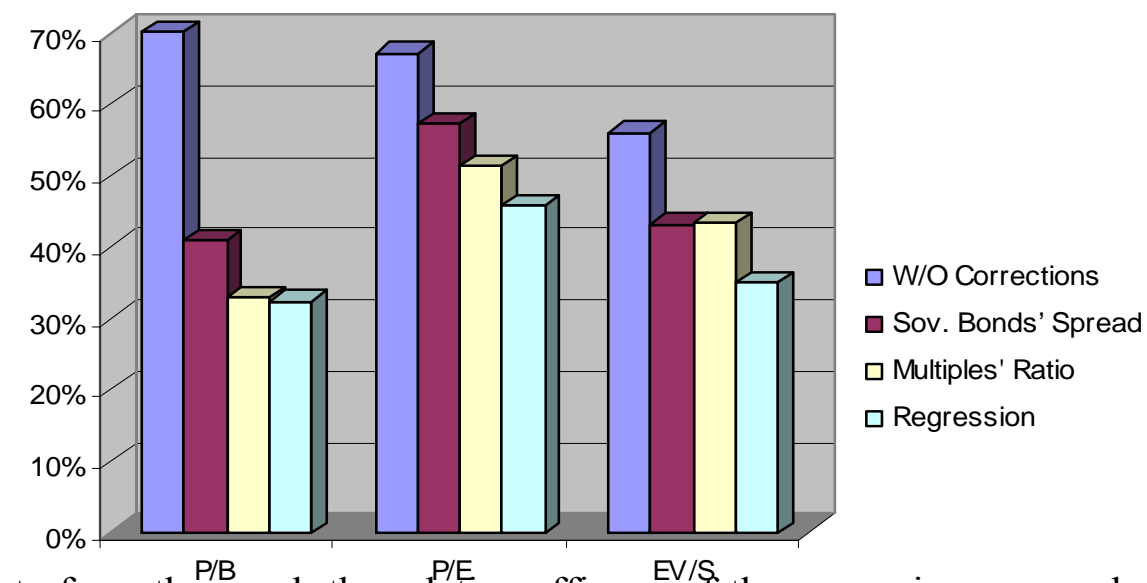

As we can state from the graph the relative efficacy of the regression approach is the highest for each multiples used, compared to the relative corrections coefficients based on the best selection criterion. For the P/B this method seems to give slightly better results than the Market Multiples Ratio. However, in terms of RMSE it prevails significantly ( 0.69 versus 0.83 ). As we can see both methods give better results compared to the Spread of the Sovereign Bonds Yield. This is probably driven by the fact that the first takes into account only the country risk, whereas the others - some additional crossborder effects as the overall difference in the Corporate Governance level or in the Sustainable Development. For the P/E multiple the regression approach is much more effective in capturing cross-border risks, than the Market Multiples Ratio. The Spread of the Sovereign Bonds Yield is ranked third. For the EV/S multiple both relative methods are equivalent, but lose significantly to the regression approach.

This figure once more shed light on the existence of some hidden cross border effects, which can be neutralized by different correction procedures. As we can see without any correction the valuation accuracy is terrible. The best correction procedure is the regression approach, which is then followed by the Market Multiples Ratio and the Spread of the Sovereign Bonds Yield methods. This is probably driven by the fact, that due to its theoretical justification, this method succeeds better in capturing the stated effects. Moreover, the valuation accuracy is better when using the $\mathrm{P} / \mathrm{B}$ and $\mathrm{EV} / \mathrm{S}$ multiples, whereas the $\mathrm{P} / \mathrm{E}$ multiple gives the worst results. This fact is replicated for each correction procedure and is consistent with practical recommendations which advise to use the $\mathrm{P} / \mathrm{B}$ multiple for manufacturing companies, which constitute the majority in our restricted sample.

Thus, we have presented a valuation methodology which can effectively be used in valuing companies from emerging markets. This model also accounts for the difference between some crucial cross-border effects which have shown a significant impact on the whole valuation methodology. 


\section{Conclusions}

In this paper we have investigated the issue of multiples valuation on emerging markets. In the case of the absence of comparable firms on the domestic market, the analyst is usually looking for peers companies from the developed counterparts. However, the emerging market is determined by several market imperfections, like barriers to entry, information asymmetry, economic and political risk, government regulations. Such factors affect the difference in the investor's perceptions of the value of same traded assets and could be attributable to country risks, which usually can be identified. However, there exist other firm-specific effects which influence significantly the company's value. They can be, for example, related to the general corporate governance level. The combination of these effects has a crucial impact on the overall valuation algorithm. That is why companies with comparable fundamentals parameters bear different values on different stock markets.

We have documented that in overall, the multiples from the developed markets have much higher values than those from the emerging ones. A possible explanation could be that companies operating on the emerging markets have different, or simply lower operational characteristics. I order to exclude this hypothesis, we used a valuation algorithm, which selected comparables companies, based on similar fundamentals (both for the US and the Russian markets), and then showed that, even after controlling for similar level of keys fundamentals (such as return on equity, expected value of Net Income growth and firm profitability) the potential bias for overvaluation remains.

Thus, it is clear that using multiples of comparable companies from the developed markets will lead to significant overvaluation. In order to deal with such problem several cross-border corrections were implemented. In order to empirically asses the magnitude of these effects, we built two valuation methodologies. The relative corrections algorithm analyzed the efficacy of the Market Multiples Ratio and the Spread of the Sovereign Bonds Yield methods as well as different comparables companies' selection criteria. We have identified that the selection criteria based on choosing comparable companies having similar fundamentals characteristics perform better than the simple industrial belonging, which was an evident proof of the previous reasoning. For the $\mathrm{P} / \mathrm{B}$ and the $\mathrm{EV} / \mathrm{S}$ multiples the fundamentals method gave better results, for the $\mathrm{P} / \mathrm{E}$ - the combined selection method based on industrial belonging and on similar fundamentals values. The use of relative corrections significantly reduced the overvaluation bias expressed in the median value of predictions errors. The Market Multiples Ratio method gave better results for the $\mathrm{P} / \mathrm{B}$ and $\mathrm{P} / \mathrm{E}$ multiples, the Spread of the Sovereign Bonds Yield methods for the $\mathrm{EV} / \mathrm{S}$.

The other valuation methodology was based on a regression approach which effectively incorporated the multiples fundamentals relationship and the corrections for cross-border effects. Based on the regression analysis we objectively proved the existence of such effects and were able to draw final conclusions about the optimal valuation methodology as well as correction procedure.

The regression approach was chosen as the best valuation tool which effectively dealt with the cross-border differences. The Market Multiples Ratio was ranked second and then followed by the Spread of the Sovereign Bonds Yield method. This is probably driven by the fact, that due to its theoretical justification, the regression method succeeds better in capturing the stated combined cross-border effects.

Moreover, we were able to determine that the valuation accuracy is better when using the $\mathrm{P} / \mathrm{B}$ and $\mathrm{EV} / \mathrm{S}$ multiples, whereas the $\mathrm{P} / \mathrm{E}$ multiple gives the worst results. This fact is replicated for each correction procedure and is consistent with practical recommendations which advise to use the $\mathrm{P} / \mathrm{B}$ multiple for manufacturing companies, which constituted the majority of our restricted sample. 
However, our approach has several limitations. First, we compared a limited amount of emerging markets. In order to extent our conclusion it is necessary to enlarge the sample of the analyzed emerging countries. By doing so we could strengthen the Spread of the Sovereign Bonds Yield method by theoretically deriving the correct correction coefficient, explained by the difference in economical countries' parameters.

Second, we restricted our sample to Russian firms reporting their accounting into the US GAAP or IAS. In case of including other Russian companies, or precisely those who reported their accounting in RAS (Russian Accounting Standards) we could expect to have lower corrections values for the Market Multiples Ratio. This is linked to the fact, that the excluded companies are mainly middle and small sized firms, whose businesses don't have any international character, which probably means an increase of companies lying into the left tail of the multiples distribution. From that point the Market Multiples Ratio could also not be considered as a reliable correction procedure.

Third, as a proxy for the expected growth rate of Net Income we have used its realized future value, which could be in fact a poor substitute. The better would be using the analysts' projections on the companies' future profitability. However, even with such substitutes we get satisfactory valuation accuracy, that is why we expect to have better estimates while using the recommended variables.

Fourth, we believe that a more thought-out incorporation and distinction of the firm-specific risks can significantly improve the valuation accuracy.

However, even with such limitations we were successful enough to elaborate a valuation methodology which can effectively be used in valuing companies from emerging markets. 


\section{References}

Books:

1. Damodaran A., Investment valuations. John Wiley \& Sons Inc; 2nd edition (2004)

2. Pereiro L.E., Valuation of Companies in Emerging Markets. A practical approach; John Wiley\&Sons, Inc., New York (2002)

Papers:

1. Alford A.W. (1992) The Effect of the Set of Comparable Firms on the Accuracy of the Price Earnings Valuation Method. Journal of Accounting Research 30, (94-108)

2. Allen A.C., Cho J.Y. (1999), Determinants of price-earnings ratios: further evidence. Southern Bus. Econ. J., (170-184)

3. Baker M. R., Ruback R. (1999), Estimating industry multiples. Working Paper, Harvard Business School, Boston

4. Bhojraj S., C.M.C. Lee (2002), Who Is My Peer? A Valuation-based Approach to the Selection of Comparable Firms. Journal of Accounting Research 40, (407-439).

5. Black B. (2001), The Corporate Governance Behavior and Market Value of Russian Firms. Emerging Markets Review Vol. 2, (1-24).

6. Boatsman J., Baskin E. (1981), Asset Valuation with Incomplete Markets. The Accounting Review 56 (38-53)

7. Erb C.B., Harvey C.R., Viskanta T.E. (1996), Political risk, economic risk, and financial risk. Financial Analysts Journal Vol. 52 Issue 6, (29-46)

8. Herrmann V., Richter F. (2003) Pricing with performance-controlled multiples. Schmalenbach Business Review. Vol. 55 (194-219)

9. Kim, M., Ritter J.R. (1999). Valuing IPOs. Journal of Financial Economics 53, (409-437)

10. Lie E., Lie H. J. (2002), Multiples Used to Estimate Corporate Value. Financial Analysts Journal, Vol. 58 Issue 2, (44-54)

11. Liu J., Nissim D., Thomas J. (2002), Equity Valuation Using Multiples. Journal of Accounting Research 40, (135-72)

12. Maug E., Dittmann I. Valuation Biases, Error Measures, and the Conglomerate Discount. Draft: February 14, 2006

13. Nikbakht E., Polat C. (1998). A global perspective of P-E ratio determinants: the case of ADRS. Global Finance Journal 9 (253-267).

14. Oppong A. (1993). Price-earnings research and the emerging capital markets: the case of Zimbabwe. International Journal of Accounting, Vol. 28 Issue 1, (71-77).

15. Ramcharran H. (2002), An empirical analysis of the determinants of the $P / E$ ratio in emerging markets. Emerging Markets Review, Volume 3, Issue 2 (165-178)

16. Zarowin P. (1990), What determines earnings-price ratios: Revisited in: Journal of Accounting, Auditing \& Finance, Vol. 5 (439-454)

Web sites:

http://www.mscibarra.com/products/gics/structure.jsp

http://www.alfabank.ru 


\section{Appendixes} 2004

Appendix \#1: Multiples Distributions across U.S. Market through Years 2002-

Figure \#4: Distributions of the EV/S multiples for the U.S. market for years 2002-2004

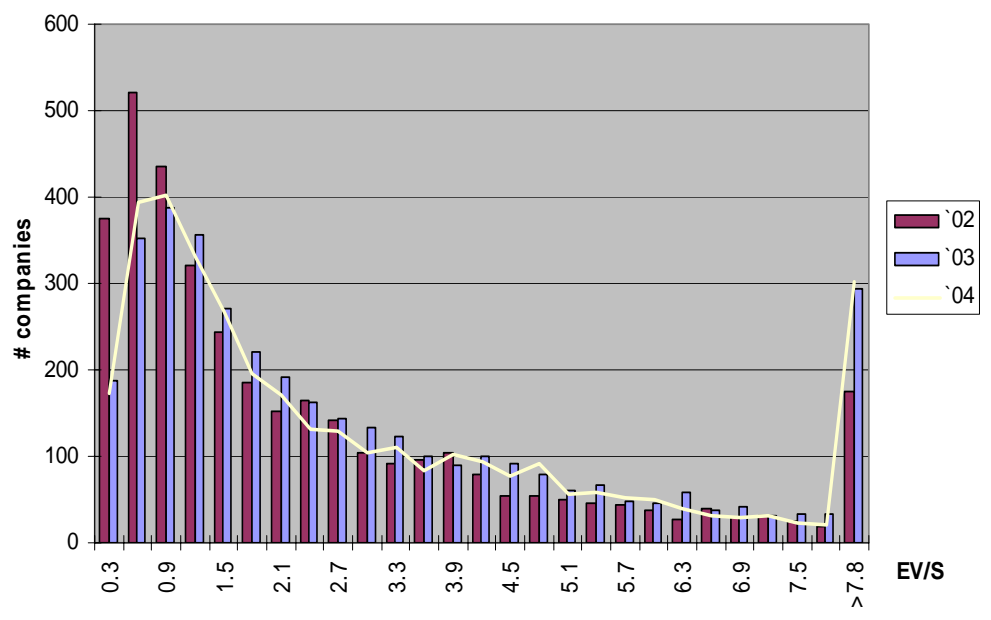

Figure \#5: Distributions of the EV/S for the Russian market for merged years 2001-2004

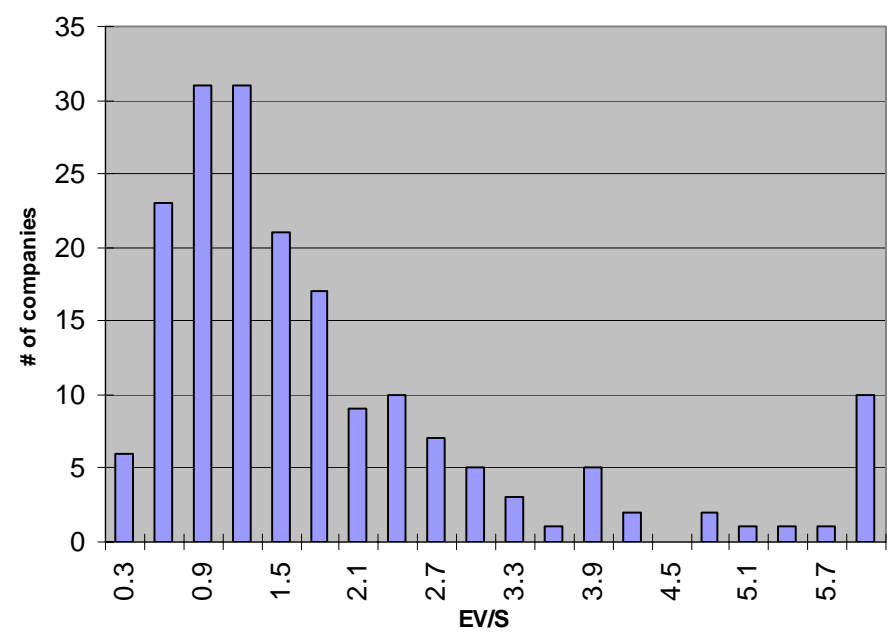


Appendix \#2: Data on U.S. Treasury Notes and Minfin's Eurobonds at 29 April 2003-2005.

Table \#10: Financial Instruments at 28.04.03

\begin{tabular}{lcrr}
\hline $\begin{array}{c}\text { Instrument's } \\
\text { Name }\end{array}$ & $\begin{array}{c}\text { Maturity } \\
\text { Date }\end{array}$ & $\begin{array}{c}\text { Yield to } \\
\text { Maturity } \\
(\%)\end{array}$ & $\begin{array}{c}\text { Maturity } \\
\text { Term (years) }\end{array}$ \\
\hline Euro-03 & 10.06 .2003 & 4.9 & 0.12 \\
Euro-05 & 24.07 .2005 & 3.7 & 2.24 \\
Euro-07 & 26.06 .2007 & 4.9 & 4.16 \\
Euro-10 & 31.03 .2010 & 5.3 & 6.93 \\
Euro-18 & 24.07 .2018 & 7.4 & 15.25 \\
Euro-28 & 24.06 .2028 & 7.9 & 25.18 \\
Euro-30 & 31.03 .2030 & 7.7 & 26.94 \\
US TN-5 & 28.04 .2007 & 2.8 & 5.00 \\
\hline
\end{tabular}

(6) $Y T M=4.35+0.14 T ; R^{2}=87 \%$

Table \#11: Financial Instruments at 29.04.04

\begin{tabular}{llrr}
$\begin{array}{l}\text { Instrument's } \\
\text { Name }\end{array}$ & $\begin{array}{c}\text { Maturity } \\
\text { Date }\end{array}$ & $\begin{array}{c}\text { Yield to } \\
\text { Maturity (\%) }\end{array}$ & $\begin{array}{c}\text { Maturity Term } \\
\text { (years) }\end{array}$ \\
\hline Euro-05 & 24.07 .2005 & 3.2 & 1.24 \\
Euro-07 & 26.06 .2007 & 5.1 & 3.16 \\
Euro-10 & 31.03 .2010 & 5.4 & 5.92 \\
Euro-18 & 24.07 .2018 & 7.6 & 14.24 \\
Euro-28 & 24.06 .2028 & 8.2 & 24.17 \\
Euro-30 & 31.03 .2030 & 7.6 & 25.94 \\
US TN-5 & 29.04 .2008 & 3.7 & 5.00 \\
\hline
\end{tabular}

(7) $Y T M=2.99+1.56 \ln T ; R^{2}=96 \%$

Table \#12: Financial Instruments at 29.04.05

\begin{tabular}{lcrrr}
\hline $\begin{array}{c}\text { Instrument's } \\
\text { Name }\end{array}$ & $\begin{array}{c}\text { Maturity } \\
\text { Date }\end{array}$ & $\begin{array}{c}\text { Yield to } \\
\text { Maturity } \\
(\%)\end{array}$ & $\begin{array}{c}\text { Maturity } \\
\text { Term (years) }\end{array}$ \\
\hline Euro-05 & 24.07 .2005 & 3.8 & 0.24 \\
Euro-07 & 26.06 .2007 & 4.7 & 2.16 \\
Euro-10 & 31.03 .2010 & 4.9 & 4.92 \\
Euro-18 & 24.07 .2018 & 6.2 & 13.24 \\
Euro-28 & 24.06 .2028 & 6.7 & 23.17 \\
Euro-30 & 31.03 .2030 & 6.2 & 24.94 \\
US TN-5 & 29.04 .2009 & 3.9 & 5.00 \\
\hline
\end{tabular}

(8) $Y T M=4.43+0.6 \ln T ; R^{2}=91 \%$ 
Appendix \#3: Regression Approach for Cross-border Corrections: 2004.

Estimated Regression Models for $\mathrm{P} / \mathrm{B}, \mathrm{P} / \mathrm{E}$ and EV/S multiples at years 2002-

(9) $\ln \left(P / B_{i}\right)=\beta_{1}+\beta_{2} \ln \left(R O E_{i}\right)+\beta_{3} \ln \left(\sigma_{N I_{i}}\right)+\beta_{4} D_{\text {country }_{i}}+\beta_{5} D_{\text {industry }_{i}}+\varepsilon_{i}$

\begin{tabular}{|c|c|c|c|c|c|c|}
\hline \multicolumn{7}{|c|}{ P/B multiple } \\
\hline Year & Intercept & $\begin{array}{l}\mathrm{Ln} \\
\mathrm{ROE}\end{array}$ & $\begin{array}{c}\mathrm{Ln} \\
\sigma \mathrm{NI}\end{array}$ & $\begin{array}{c}\beta \\
\text { country }\end{array}$ & $\begin{array}{c}\beta \\
\text { industry }\end{array}$ & Rsq \\
\hline \multirow[t]{2}{*}{2004} & 0.80 & 0.33 & -0.03 & 0.54 & 0.02 & 0.39 \\
\hline & $(0.168)$ & $(0.036)$ & $(0.016$ & $0.097)$ & $(0.028)$ & \\
\hline \multirow[t]{2}{*}{2003} & 1.35 & 0.37 & 0.01 & 0.20 & -0.03 & 0.41 \\
\hline & $(0.185)$ & $(0.036)$ & $(0.017)$ & $(0.110)$ & $(0.031)$ & \\
\hline \multirow[t]{2}{*}{2002} & 0.24 & 0.28 & 0.06 & 0.74 & -0.03 & 0.40 \\
\hline & $(0.189)$ & $(0.036)$ & $(0.017)$ & $(0.126)$ & $(0.032)$ & \\
\hline \multirow[t]{2}{*}{ Merged } & 0.36 & 0.16 & 0.03 & 0.41 & -0.02 & 0.30 \\
\hline & $(0.079)$ & $(0.017)$ & $(0.007)$ & $(0.045)$ & $(0.013)$ & \\
\hline
\end{tabular}

$\left(1 \mathrm{Al}\left(P / E_{i}\right)=\beta_{1}+\beta_{2} N I_{\text {growth }_{i}}+\beta_{3} \ln \left(\sigma_{N I_{i}}\right)+\beta_{4} D_{\text {country }_{i}}+\beta_{5} D_{\text {industry }_{i}}+\varepsilon_{i}\right.$

\begin{tabular}{|c|c|c|c|c|c|c|}
\hline \multicolumn{7}{|c|}{ P/E multiple } \\
\hline Year & Intercept & $\begin{array}{c}\text { NI } \\
\text { growth }\end{array}$ & $\begin{array}{c}\mathrm{Ln} \\
\sigma \mathrm{NI}\end{array}$ & $\begin{array}{c}\beta \\
\text { country }\end{array}$ & $\begin{array}{c}\beta \\
\text { industrv }\end{array}$ & Rsq \\
\hline 2004 & $\begin{array}{r}2.48 \\
(0.136)\end{array}$ & $\begin{array}{r}-0.09 \\
(0.090)\end{array}$ & $\begin{array}{r}-0.04 \\
(0.017)\end{array}$ & $\begin{array}{r}0.33 \\
(0.099)\end{array}$ & $\begin{array}{r}-0.04 \\
(0.028)\end{array}$ & 0.18 \\
\hline 2003 & $\begin{array}{r}2.57 \\
(0.131)\end{array}$ & $\begin{array}{r}0.08 \\
(0.029)\end{array}$ & $\begin{array}{r}-0.02 \\
(0.014)\end{array}$ & $\begin{array}{r}0.24 \\
(0.096)\end{array}$ & $\begin{array}{r}-0.01 \\
(0.024)\end{array}$ & 0.11 \\
\hline 2002 & $\begin{array}{r}2.17 \\
(0.134) \\
\end{array}$ & $\begin{array}{r}0.06 \\
(0.059) \\
\end{array}$ & $\begin{array}{r}0.01 \\
(0.017) \\
\end{array}$ & $\begin{array}{r}0.45 \\
(0.103) \\
\end{array}$ & $\begin{array}{r}-0.05 \\
(0.029) \\
\end{array}$ & 0.16 \\
\hline Merged & $\begin{array}{r}2.35 \\
(0.082)\end{array}$ & $\begin{array}{r}0.10 \\
(0.027)\end{array}$ & $\begin{array}{r}-0.02 \\
(0.009)\end{array}$ & $\begin{array}{r}0.45 \\
(0.060)\end{array}$ & $\begin{array}{r}-0.03 \\
(0.016)\end{array}$ & 0.16 \\
\hline
\end{tabular}

(11) $E V / S_{i}=\beta_{1}+\beta_{2} O M_{i}+\beta_{3} \ln \left(\sigma_{E B I T_{i}}\right)+\beta_{4} D_{\text {country }_{i}}+\beta_{5} D_{\text {industry }_{i}}+\varepsilon_{i}$

\begin{tabular}{|c|c|c|c|c|c|c|}
\hline \multicolumn{7}{|c|}{ EV/S multiple } \\
\hline Year & Intercept & OM & Ln $\sigma \mathrm{EBIT}$ & $\beta$ country & $\beta$ industry & Rsq \\
\hline \multirow[t]{2}{*}{2004} & 1.26 & 2.85 & 0.08 & 0.42 & -0.22 & 0.26 \\
\hline & $(0.197)$ & $(0.777)$ & $(0.023)$ & $(0.136)$ & $(0.037)$ & \\
\hline \multirow[t]{2}{*}{2003} & 1.19 & 6.85 & 0.07 & 0.26 & -0.19 & 0.41 \\
\hline & $(0.169)$ & $(0.874)$ & $(0.021)$ & $(0.112)$ & $(0.034)$ & \\
\hline \multirow[t]{2}{*}{2002} & 0.52 & 6.73 & 0.12 & 0.65 & -0.18 & 0.44 \\
\hline & $(0.192)$ & $(0.932)$ & $(0.021)$ & $(0.131)$ & $(0.036)$ & \\
\hline \multirow[t]{3}{*}{ Merged } & 1.06 & 4.79 & 0.09 & 0.43 & -0.19 & 0.32 \\
\hline & $(0.11$ & $(0.47$ & $(0.01$ & $(0.07$ & $(0.02$ & \\
\hline & 0) & 9) & 3) & 5) & 1) & \\
\hline
\end{tabular}


Appendix \#4: Empirical Analysis of the Efficiency of Relative Multiples Corrections for selected Industries at Years 2002-2004.

Table \#13: Efficiency Comparison for the P/B Multiple

\begin{tabular}{l|rrrrr}
\hline \multicolumn{1}{c|}{$\begin{array}{c}\text { Correction } \\
\text { procedure }\end{array}$} & Mean & Median & Abs. Median & RMSE & Std. dev \\
\hline W/O Corrections & $104 \%$ & $77 \%$ & $75 \%$ & 1.82 & 1.50 \\
Sov. Bonds Spread & $31 \%$ & $18 \%$ & $41 \%$ & 0.92 & 0.87 \\
Multiples Ratio & $23 \%$ & $15 \%$ & $\underline{\mathbf{3 3 \%}}$ & $\underline{\mathbf{0 . 8 3}}$ & 0.80 \\
\hline
\end{tabular}

\begin{tabular}{l|rrrrr|}
\hline \multicolumn{1}{|c|}{$\begin{array}{c}\text { Correction } \\
\text { procedure }\end{array}$} & Meandustry Code and Fundamentals Filter Method \\
\hline W/O Corrections & $121 \%$ & $81 \%$ & $90 \%$ & 2.16 & 1.81 \\
Sov. Bonds Spread & $41 \%$ & $22 \%$ & $44 \%$ & 1.19 & 1.12 \\
Multiples Ratio & $34 \%$ & $13 \%$ & $\underline{\mathbf{4 0 \%}}$ & $\underline{\mathbf{1 . 1 2}}$ & 1.07 \\
\hline
\end{tabular}

Table \#14: Efficiency Comparison for the P/E Multiple

\begin{tabular}{|c|c|c|c|c|c|}
\hline \multirow{2}{*}{$\begin{array}{l}\text { Correction } \\
\text { procedure }\end{array}$} & \multicolumn{5}{|c|}{ Fundamentals Filter Method } \\
\hline & Mean & Median & Abs. Median & RMSE & Std. dev \\
\hline $\mathrm{W} / \mathrm{O}$ Corrections & $59 \%$ & $34 \%$ & $73 \%$ & 1.50 & 1.39 \\
\hline Sov. Bonds Spread & $6 \%$ & $-15 \%$ & $54 \%$ & 0.95 & 0.96 \\
\hline Multiples Ratio & $-5 \%$ & $-19 \%$ & $53 \%$ & $\underline{0.83}$ & 0.83 \\
\hline Correction & \multicolumn{5}{|c|}{ Industry Code and Fundamentals Filter Method } \\
\hline procedure & Mean & Median & Abs. Median & RMSE & Std. dev \\
\hline $\mathrm{W} / \mathrm{O}$ Corrections & $28 \%$ & $18 \%$ & $67 \%$ & 1.25 & 1.22 \\
\hline Sov. Bonds Spread & $-15 \%$ & $-21 \%$ & $57 \%$ & 0.84 & 0.84 \\
\hline Multiples Ratio & $-23 \%$ & $-30 \%$ & $51 \%$ & 0.77 & 0.74 \\
\hline
\end{tabular}

Table \#15: Efficiency Comparison for the EV/S Multiple

\begin{tabular}{l|rrrr|c}
\hline \multicolumn{1}{c}{$\begin{array}{c}\text { Correction } \\
\text { procedure }\end{array}$} & \multicolumn{5}{|c|}{ Fundamentals Filter Method } \\
\cline { 2 - 6 } Wean & Median & Abs. Median & RMSE & Std. dev \\
W/O Corrections & $51 \%$ & $33 \%$ & $56 \%$ & 1.05 & 0.92 \\
Sov. Bonds Spread & $-15 \%$ & $-27 \%$ & $\mathbf{4 3 \%}$ & $\underline{\mathbf{0 . 5 5}}$ & 0.53 \\
Multiples Ratio & $-13 \%$ & $-26 \%$ & $43 \%$ & 0.57 & 0.56 \\
\hline
\end{tabular}

\begin{tabular}{l|rrrrr|}
\hline \multirow{2}{*}{$\begin{array}{l}\text { Correction } \\
\text { procedure }\end{array}$} & \multicolumn{4}{|c}{ Industry Code and Fundamentals Filter Method } \\
\cline { 2 - 6 } & Mean & Median & Abs. Median & RMSE & Std. dev \\
\hline W/O Corrections & $53 \%$ & $17 \%$ & $58 \%$ & 1.41 & 1.31 \\
Sov. Bonds Spread & $0 \%$ & $-26 \%$ & $\underline{\mathbf{4 8 \%}}$ & $\underline{\mathbf{0 . 8 6}}$ & 0.87 \\
Multiples Ratio & $4 \%$ & $-24 \%$ & $51 \%$ & 0.90 & 0.90 \\
\hline
\end{tabular}

